\title{
Resenha do livro $O$ livro aberto: leituras da Bíblia. Rio de Janeiro: Oficina Raquel, 2017, de Frederico Lourenço
}

\author{
Book review of 0 livro aberto: leituras da Bíblia. Rio de \\ Janeiro: Oficina Raquel, 2017, by Frederico Lourenço.
}

Reseña del libro 0 livro aberto: leituras da Bíblia. Rio de Janeiro: Oficina Raquel, 2017, de Frederico Lourenço

Anderson de Oliveira Lima*

\begin{abstract}
RESUMO
Resenha do livro: LOURENÇO, Frederico. O livro aberto: leituras da Bíblia. Rio de Janeiro: Oficina Raquel, 2017, 143p.

ABSTRACT

Book review of: LOURENÇO, Frederico. O livro aberto: leituras da Bíblia. Rio de Janeiro: Oficina Raquel, 2017, 143p. [The open book: Bible readings].

RESUMEN

Reseña del libro: LOURENÇO, Frederico. O livro aberto: leituras da Bíblia. Rio de Janeiro: Oficina Raquel, 2017, 143p. [El libro abierto: lecturas de la Biblia].
\end{abstract}

O livro aberto: leituras da Bíblia é o título da obra de Frederico Lourenço que a editora Oficina Raquel publicou em 2017 na cidade do Rio de Janeiro. Nascido em Lisboa em 1963, o autor é doutor em Literatura Grega, professor de Estudos Clássicos da Universidade de Coimbra e tem seu nome conhecido no Brasil por ser o tradutor das obras homéricas, publicadas pela editora Companhia das Letras. Atualmente Lourenço trabalha numa esperada tradução da Bíblia que teve seus dois primeiros volumes (dos 6 previstos) lançado no Brasil, também pela Companhia das Letras, em 2017 e 2018, respectivamente. Vê-se que é como competente tradutor que Frederico Lourenço tem chamado a atenção do nosso mercado editorial, o que suscita mais curiosidade quanto a este novo livro que se apresenta como uma série de breves ensaios escritos pelo autor a partir das leituras de passagens escolhidas dos textos bíblicos.

No Prefácio (LOURENÇO, 2017, p. 11-13) o autor afirma que "A Bíblia pode ser lida de muitas maneiras" e define seu próprio modo de lê-la dizendo

* Pós-doutorando do Programa de Pós-graduação em Ciências da Religião da PUC-Campinas. 
que sua abordagem não é religiosa, tampouco, irreligiosa. Ao longo do livro Lourenço se define como um agnóstico para o qual Deus, existindo, “terá provavelmente de corresponder a uma realidade bem diferente daquela que imaginaram os autores da Bíblia” (p. 73). Pode-se dizer que ele, diferente dos religiosos, lê a Bíblia como um livro comum, mas partindo de um juízo prévio, pessoal e muito positivo sobre seu valor como patrimônio cultural da humanidade:

[...] a Bíblia pode ser lida como o mais fascinante livro alguma vez escrito; um texto que, no seu melhor, é de riqueza inesgotável, de ímpar magnificência expressiva, e onde encontramos do mais arrebatador e do mais comovente que a mente humana alguma vez terá conseguido imaginar. (p. 12)

Os dois primeiros capítulos (p. 15-24), com propósitos introdutórios, foram construídos para discutir possíveis usos dos textos bíblicos. Neles o autor aborda rapidamente as leituras religiosas fundamentalistas que levam muito a sério os textos, que são tomados como artefatos sagrados, interpretando-os ao pé da letra. É relevante, neste ponto, que Lourenço reconheça que é assim que os próprios textos bíblicos querem ser lidos; ele é forçado a admitir que tais leitores respondem adequadamente aos textos que leem, embora assim agindo tenham que lidar com a impossível tarefa de praticar suas religiosidades - originadas num mundo arcaico e ficcional - no mundo contemporâneo e real. O autor também fala das práticas modernas de leitura, dos usos descompromissados que veem a Bíblia tão somente como ficção e a tomam parcialmente, aplicam-na conforme seus interesses, fruem-na na medida de seus desejos.

Diante da aparente necessidade de escolher uma dessas duas práticas de leitura, Frederico Lourenço se abstêm: nem reconhece a sacralidade do texto, que exigiria a submissão do leitor, nem considera apropriada a fácil relativização ou alegorização; ele apenas declara: "considero o tempo gasto a ler este mais fascinante de todos os livros tempo ganho e (por que não?) infalivelmente bem empregue" (p. 20). Essa nos pareceu ser uma saída peculiar, saída que não é religiosa, tampouco desinteressada. Sua prática de leitura talvez possa ser explicada como uma espécie de devoção ao ser humano e sua capacidade criativa, à sua potencialidade expressiva que se manifesta na literatura, o que resulta numa forma de leitura intensiva, empenhada e também deslumbrada.

Essa relação emocional do autor para com o texto bíblico, esse sentimento de deleite e gratidão pela presença das tradições bíblicas na cultura ocidental, se revela noutros pontos do livro O livro aberto. Por exemplo, o 
capítulo 5, que trata do modo como fontes diversas (e não apenas bíblicas) foram usadas para dar origem à cena do presépio como hoje nos apresentam as esculturas natalinas, começa assim:

Se me perguntarem qual é o texto mais encantador alguma vez escrito em língua grega, a minha resposta só pode ser esta: é o início do evangelho de Lucas, concretamente os seus capítulos 1 e 2 [...] Sem o relato de Lucas, a arte ocidental teria tido uma história infinitamente mais pobre. (p. 35)

Assim vai o autor comentando de forma bastante espontânea e apaixonada alguns livros bíblicos ao longo dos 25 breves capítulos de O livro aberto. Nota-se que a eleição dos temas comentados dependeu unicamente dos interesses pessoais de Lourenço, de modo que há uma predominância de textos que discutem as passagens bíblicas que se revelam contrárias à tradição católica que, em Portugal, toca o autor de modo especial. Isso é o que determina, por exemplo, a abordagem do capítulo 22, intitulado: "Aos tropeços na leitura dos evangelhos" (p. 111-115). Aí podemos ver como chama a atenção do autor cada linha dos evangelhos em que ele descobre quão distante está a doutrina católica das palavras bíblicas. Frederico Lourenço se ocupa muitas vezes com as narrativas bíblicas que atualmente são consideradas historicamente implausíveis, dedicando tempo em discussões que, em boa medida, reproduzem debates bem conhecidos dos estudos acadêmicos relativos à Bíblia.

Particularmente incômodo em nossa experiência com o livro foi encontrar, no capítulo 24, a ideia de que o Evangelho de João seja o preferido do autor (em relação aos demais evangelhos) por seu suposto "valor objetivo e histórico-documental". A preferência decorre do fato de Lourenço encarar o quarto evangelho como produto de alguém que foi testemunha ocular dos eventos narrados (p. 120-121), conclusão que se apoia em hipóteses que atualmente não recebem grande apoio por parte dos especialistas em estudos bíblicos. O que se pode pensar é que Lourenço, que não é alguém que se dedica exclusivamente à Bíblia, está se inserindo gradativamente nas pesquisas bíblicas, pelo que sua produção, que em $O$ livro aberto ainda deixa ver problemas teóricos, deve ganhar qualidade à medida que ele segue traduzindo e estudando os livros bíblicos e a literatura especializada.

Como era de se esperar, as principais contribuições do autor se localizam nos capítulos em que ele se ocupa com o texto grego do Novo Testamento, com as peculiaridades da língua grega e sobre as ricas possiblidades interpretativas que só quem é capaz de ler o texto bíblico em seu idioma original pode acessar. Neste sentido, o Apêndice (p. 131-140), que foi dedicado a comentários sobre diversas peculiaridades do grego bíblico se mostra como 
uma das partes mais relevantes da obra. Também provocam admiração, por esse mesmo motivo, os capítulos 7 e 23 .

Impressão bastante positiva nos causou a leitura dos capítulos 9, "O escravo e sua sombra", e 25, "Sepultar Jesus (em três etapas)". Neles o autor não se prende tanto às questões de historicidade dos livros bíblicos, não se ocupa tanto com o grego do Novo Testamento nem com as apropriações católicas da tradição bíblica. Aplicando um método diferente o autor lida rapidamente com as histórias bíblicas e com algumas de suas recepções para refletir sobre a vida, sobre a humanidade, sobre a violência, a escravidão e o sofrimento. O texto bíblico é, nestes casos, o lugar de onde o pensador extrai seus temas para discutir as dores do mundo, as riquezas de sua cultura, as mazelas de sua espécie etc.

Antes de encerrarmos, vale a pena dizer que o trabalho de adaptação do texto ao português brasileiro deixou a desejar em $O$ livro aberto. Ficaram no texto muitos resquícios da língua falada em Portugal e um bom número de pequenos erros. Há ainda uma dificuldade com as citações feitas pelo autor em latim, inglês e francês e que não foram traduzidas para o português, o que não é uma prática comum no cenário editorial brasileiro.

A obra merece nossa atenção por ser uma das poucas iniciativas que conhecemos no Brasil de uma apropriação laica da tradição bíblica. A despeito de nossas elevadas expectativas, trata-se de uma abordagem competente, embora nem sempre original, cujo mérito se deve principalmente à grande competência do autor no trato com o grego antigo. Não há dúvidas de que a grande contribuição de Frederico Lourenço aos estudos da Bíblia no Brasil se dará mesmo com a publicação dos 6 volumes de sua tradução do Novo Testamento e da Septuaginta; no entanto, sempre serão bem-vindas obras que, como essa, dão-nos algum acesso aos elementos dos textos bíblicos que chamam a atenção de leitores tão singulares quanto Lourenço. E como este autor faz questão de deixar em seu livro uma série de dados biográficos, torna-se também curioso observar como esse indivíduo encara essa literatura tão visitada, como dialoga com os usos tradicionais, religiosos, que procedimentos emprega na solução de seus próprios problemas, na elaboração dos próprios caminhos interpretativos... Enfim, além da inegável contribuição que Lourenço nos dá em cada comentário que faz sobre o grego do Novo Testamento, julgamos $O$ livro aberto uma obra de especial valor para aqueles que se interessam pela história da leitura bíblica e pelas múltiplas maneiras de lê-la. Temos, nas suas 143 páginas, um bom material para o estudo de uma apropriação contemporânea (e laica) da tradição bíblica.

Submetida em: 5-7-2018

Aceita em: 20-12-2018 